\title{
Genital warts: need to screen for coinfection
}

\author{
C A Carne, G Dockerty
}

Patients with genital warts should attend a genitourinary medicine clinic for tracing of contacts and screening for coinfection
Department of Genitourinary Medicine, Addenbrooke's Hospital, Cambridge CB2 2QQ C A Carne, MD, consultant G Dockerty, SEN, acting charge nurse

BrMed f 1990;300:459
The incidence of genital warts has increased rapidly over the past 10 to 12 years. Data from genitourinary medicine clinics show that rates per 100000 population have increased from 84.3 in 1977 to 260.1 in $1987 .{ }^{1}$ In 1987,74542 people attended genitourinary medicine clinics with a new diagnosis of genital warts. ${ }^{1}$ Most interest in the condition has concerned the link between the aetiologic agent of warts, human papillomavirus, and the development of cervical cancer. ${ }^{2}$ The link between the virus and other sexually transmitted diseases, however, is also of major importance. The most recently published comprehensive survey of the incidence of associated genital infections in patients with genital warts was performed in 1976 without the benefit of screening for chlamydia.

\section{Subjects, methods, and results}

In 1988 at this clinic genital warts were diagnosed in 179 men and 168 women who had never previously attended the clinic. All men were screened for urethral gonorrhoea (by Gram staining, culture on Bacto GC medium, detection of antigen by immunofluorescence, and confirmation by sugar fermentation tests) and urethral Chlamydia trachomatis (by enzyme linked immunosorbent assay (ELISA), Celltech, Boots). All women were screened for cervical and urethral gonorrhoea and cervical chlamydia (as above). Vaginal smears were taken to detect candida (by Gram staining) and Trichomonas vaginalis (by low power microscopic examination of wet films) and for culture of both organisms on Feinberg-Whittington medium, plus detection of bacterial vaginosis (by Gram staining for "clue cells" and Gram variable coccobacilli and by the potassium hydroxide amine test). All patients were screened for syphilis with the Venereal Disease Research Laboratory test and Treponema pallidum haemagglutination assay. Other tests such as culture for herpes virus were performed as indicated by symptoms and signs.

Seventy coincident conditions were found in 60 (34\%) of the 179 men and 122 in $91(54 \%)$ of the 168 women. Fifty six $(80 \%)$ of the coincident conditions in men were sexually transmitted diseases compared with $46(51 \%)$ of those in women (table). The incidence of a coincident sexually transmitted disease was the same in men $(36 / 179,20 \%)$ and women $(34 / 168,20 \%)$.

\section{Discussion}

Infection with genital warts was the only sexually transmitted disease, except for the uncommon condition of genital molluscum contagiosum, to show an increase in incidence among attenders at genitourinary medicine clinics in England between 1986 and $1987 .{ }^{1}$ The high rate of associated infections shown in new patients attending with genital warts is important for two reasons. Firstly, many of the coinfections are sexually transmitted, and therefore tracing of contacts is required. Many similar patients are seen in general practice and gynaecology outpatient departments where the facilities for screening for coinfection are less good than in genitourinary medicine clinics and the infrastructure for tracing contacts is non-existent.

Coincident infections in patients with genital warts. (Figures in parentheses are percentages of total patients in group)

\begin{tabular}{lccc}
\hline & $\begin{array}{c}\text { Men } \\
(\mathrm{n}=179)\end{array}$ & $\begin{array}{c}\text { Women } \\
(\mathrm{n}=168)\end{array}$ & $\begin{array}{c}\text { Total } \\
(\mathrm{n}=347)\end{array}$ \\
\hline Chlamydia & $24(13 \cdot 4)$ & $31(18 \cdot 5)$ & $55(15 \cdot 9)$ \\
Candida & $6(3 \cdot 4)$ & $46(27 \cdot 4)$ & $52(15 \cdot 0)$ \\
Non-specific genital infection & $22(12 \cdot 3)$ & $3 \star(1 \cdot 8)$ & $25(7 \cdot 2)$ \\
Bacterial vaginosis & 0 & $10(6 \cdot 0)$ & $10(2 \cdot 9)$ \\
Pelvic inflammatory disease & $1(0 \cdot 6)$ & $5(2 \cdot 0)$ & $5(\mathrm{NA})$ \\
Genital herpes & 0 & $2(1 \cdot 2)$ & $\begin{array}{r}5(1 \cdot 4) \\
2(0 \cdot 6)\end{array}$ \\
Trichomonas & $2(1 \cdot 1)$ & & $2(\mathrm{NA})$ \\
Non-candidal balanitis & $2(1 \cdot 1)$ & 0 & $2(0 \cdot 6)$ \\
Pubic lice & $1(0 \cdot 6)$ & $1(0 \cdot 6)$ & $2(0 \cdot 6)$ \\
Gonorrhoea & $9(5 \cdot 0)$ & $14(8 \cdot 3)$ & $23(6 \cdot 6)$ \\
Other conditions: & $3(1 \cdot 7)$ & $6(3 \cdot 6)$ & $9(2 \cdot 6)$ \\
$\quad$ Requiring treatment & 70 & 122 & 192 \\
$\quad$ Not requiring treatment & &
\end{tabular}

* Received epidemiological treatment as non-specific genital infection diagnosed in partners.

Secondly, coincident asymptomatic genital infection may result in serious disease. In this respect Chlamydia trachomatis is of major importance because untreated subclinical salpingitis is a common cause of infertility. ${ }^{4}$ Coincident genital infections, whether sexually transmitted or not, may be important in women because they produce a moist environment, which may play a part in encouraging proliferation of genital warts.

In Sheffield in 1976 Kinghorn surveyed accompanying genital infections diagnosed at the time of presentation with warts and found that $32 \%$ of the men and $61 \%$ of the women had a coincident genital infection; $29 \%$ of the men and $28 \%$ of the women had a coincident sexually transmitted disease. ${ }^{3}$ Demographic differences between the populations seen in Cambridge and Sheffield probably account for the differing incidence of sexually transmitted diseases diagnosed. The difference is probably even more pronounced because Kinghorn was unable to test for chlamydia.

All patients with genital warts should be referred to a genitourinary medicine clinic for at least one visit so that screening for coinfection and tracing of contacts can be performed.

1 Department of Health. New cases seen at genitourinary medicine clinics 1987. Summary information from Form SBH 60: 1987. London: DoH, 1989. Grubb GS. Human papillomavirus and cervical neoplasia: epidemiological considerations. Int $\mathcal{f}$ Epidemiol 1986;15:1-7.

Kinghorn GR. Genital warts: incidence of associated genital infections. $\mathrm{Br} \mathcal{F}$ Dermatol 1978;99:405-9.

4 Moore DE, Spadoni LR, Foy HM, et al. Increased frequency of serum antibodies to Chlamydia trachomatis in infertility due to distal tubal disease. antibodies to Chlam

5 Oriel ID. The natural history of genital warts. British fournal of Venereal Diseases 1971:47:1-13.

(Accepted 26 September 1989) 